\title{
The Secretory Granule-Associated Protein CAPS2 Regulates Neurotrophin Release and Cell Survival
}

\author{
Tetsushi Sadakata, ${ }^{1,4}$ Akira Mizoguchi, ${ }^{5}$ Yumi Sato, ${ }^{1}$ Ritsuko Katoh-Semba, ${ }^{6}$ Mitsunori Fukuda, ${ }^{2}$ \\ Katsuhiko Mikoshiba, ${ }^{3,4}$ and Teiichi Furuichi ${ }^{1}$ \\ ${ }^{1}$ Laboratory for Molecular Neurogenesis, ${ }^{2}$ Fukuda Initiative Research Unit, and ${ }^{3}$ Laboratory for Developmental Neurobiology, RIKEN Brain Science \\ Institute, Wako, Saitama 351-0198, Japan, ${ }^{4}$ Department of Molecular Neurobiology, Institute of Medical Science, The University of Tokyo, Tokyo 108-8639, \\ Japan, ${ }^{5}$ Department of Anatomy, School of Medicine, Mie University, Tsu, Mie 514-8507, Japan, and ${ }^{6}$ Department of Perinatology, Institute for \\ Developmental Research, Aichi Human Service Center, Kasugai, Aichi 480-0392, Japan
}

Neurotrophins are key modulators of various neuronal functions, including differentiation, survival, and synaptic plasticity, but the molecules that regulate their secretion are poorly understood. We isolated a clone that is predominantly expressed in granule cells of postnatally developing mouse cerebellum, which turned out to be a paralog of CAPS ( $\mathrm{Ca}^{2+}$-dependent activator protein for secretion), and named CAPS2. CAPS2 is enriched on vesicular structures of presynaptic parallel fiber terminals of granule cells connecting postsynaptic spines of Purkinje cell dendrites. Vesicle factions affinity-purified by the CAPS2 antibody from mouse cerebella contained significant amounts of neurotrophin-3 (NT-3), brain-derived neurotrophic factor (BDNF), and chromogranin B but not marker proteins for synaptic vesicle synaptophysin and synaptotagmin. In cerebellar primary cultures, punctate CAPS2 immunoreactivities are primarily colocalized with those of NT-3 and BDNF and near those of a postsynaptic marker, postsynaptic density-95, around dendritic arborization of Purkinje cells. Exogenously expressed CAPS2 enhanced release of exogenous NT-3 and BDNF from PC12 cells and endogenous NT-3 from cultured granule cells in a depolarization-dependent manner. Moreover, the overexpression of CAPS2 in granule cells promotes the survival of Purkinje cells in cerebellar cultures. Thus, we suggest that CAPS2 mediates the depolarization-dependent release of NT-3 and BDNF from granule cells, leading to regulation in cell differentiation and survival during cerebellar development.

Key words: neurotrophin; BDNF; NT-3; granule cell; Purkinje cell; parallel fiber; cerebellum; CAPS; exocytosis; secretory granule

\section{Introduction}

Neurotrophins play indispensable roles in regulating the differentiation and survival of neurons (Murphy et al., 1998; Miller and Kaplan, 2001; Ginty and Segal, 2002; Horch and Katz, 2002; Huang and Reichardt, 2002). Recent evidence indicates their modulatory roles in synaptic plasticity such as long-term potentiation relevant to learning and memory ( $\mathrm{Lu}$ and Figurov, 1997; Kovalchuk et al., 2002; Egan et al., 2003) and in neuronal diseases, including Alzheimer's disease and Parkinson's disease (Murer et al., 2001). It was reported that increasing intracellular $\mathrm{Ca}^{2+}$ regulates activity dependency on the neurotrophin release from neuronal processes (Canossa et al., 2001; Balkowiec and Katz, 2002; Wang et al., 2002). However, the underlying molecular mechanism is poorly understood.

Many reports describe how neurotrophins play important roles in the postnatal development of the cerebellum (Lindholm et al., 1993, 1997; Segal et al., 1995; Schwartz et al., 1997; Doughty

Received May 21, 2003; revised Nov. 5, 2003; accepted Nov. 5, 2003.

This study was supported by grants-in-aid for scientific research from the Japanese Ministry of Education, Culture, Sports, Science and Technology and the Japan Society for the Promotion of Science and by the Institute of Physical and Chemical Research. We thank the laboratory members for useful comments and discussion.

Correspondence should be addressed to Teiichi Furuichi, Laboratory for Molecular Neurogenesis, RIKEN Brain Science Institute, 2-1 Hirosawa, Wako, Saitama 351-0198, Japan. E-mail: tfuruichi@brain.riken.jp.

DOI:10.1523/JNEUROSCI.2528-03.2004

Copyright $\odot 2004$ Society for Neuroscience $\quad$ 0270-6474/04/240043-10\$15.00/0 et al., 1998; Bates et al., 1999). Neurotrophin-3 (NT-3) and brainderived neurotrophic factor (BDNF) show a reversed expression pattern in cerebellar granule cells; between postnatal day 10 (P10) and P20 of rat cerebellum, the former is downregulated, whereas the latter is upregulated (Rocamora et al., 1993; Katoh-Semba et al., 1997, 2000; Das et al., 2001). Both the receptors TrkB (for BDNF) (Gao et al., 1995) and TrkC (for NT-3) (Velier et al., 1997 ) are expressed in postsynaptic Purkinje cells as well as presynaptic granule cells, and BDNF and NT-3 released from granule cells are thought to function in autocrine-paracrine and anterograde manners (Lindholm et al., 1993; Mount et al., 1994; Schwartz et al., 1997; Bates et al., 1999). Analyses of mice genetically lacking the gene for NT-3 (Bates et al., 1999) and BDNF (Schwartz et al., 1997) show that these neurotrophins play pivotal roles in the survival and differentiation of these neurons. Few studies, however, have addressed how they are released from neurons.

In this study, we isolated a molecule designated a1803 by differential screening of gene expression responsible for the postnatal development of mouse cerebellum. a1803 is a paralog of CAPS $\left(\mathrm{Ca}^{2+}\right.$-dependent activator protein for secretion), which has been characterized as controlling $\mathrm{Ca}^{2+}$-dependent secretion from endocrine and neuroendocrine cells (Walent et al., 1992; Ann et al., 1997; Berwin et al., 1998; Tandon et al., 1998; Renden et al., 2001), and named CAPS2. There has been no direct evi- 
dence reported on involvement of CAPS1 in the neurotrophin release activity from neurons and neuronal cell function. In the present study, we indicate that CAPS2 is enriched on vesicular structures in the parallel fiber (PF) terminals of granule cells, and the CAPS2-associated vesicles are distinctly different from synaptic vesicles (SVs) and contain NT-3 and BDNF as well as a secretory granule (SG) marker, chromogranin B (CGB). Furthermore, we demonstrate that CAPS2 has neuronal activity that enhances neurotrophin release and promotes cell survival in cerebellar cultures.

\section{Materials and Methods}

Differential display and molecular cloning. Fluorescent differential display (FDD) and fulllength cDNA cloning were performed essentially as described by Shiraishi et al. (1999). The FDD was performed using total RNAs obtained from mouse (ICR, Nihon SLC, Hamamatsu, Japan) cerebella at eight different developmental ages: embryonic day 18 (E18), P0, P3, P7, P12, $\mathrm{P} 15, \mathrm{P} 21$, and P56. The cDNA sequence of a1803/CAPS2a (GenBank accession number AB098623) was determined using a DNA sequencer (Prism 3700; Applied Biosystems, Foster City, CA).

In situ hybridization. The cDNA sequence corresponding to amino acids $18-89$ of a 1803 / CAPS2 was used as the template to prepare the antisense riboprobe. Cryosections of mouse brain (14 $\mu \mathrm{m}$ thick) were fixed in $4 \%$ paraformaldehyde for $5 \mathrm{~min}$, washed twice in PBS, and treated with freshly prepared $10 \mu \mathrm{g} / \mathrm{ml}$ proteinase K (Invitrogen, Carlsbad, CA) at room temperature. After acetylation, sections were incubated in hybridization buffer containing 0.2 $\mu \mathrm{g} / \mathrm{ml}$ digoxigenin-labeled riboprobes at $43^{\circ} \mathrm{C}$ overnight in a humid chamber. Hybridized sections were washed by successively immersing in $4 \times$ SSC (in mM: $150 \mathrm{NaCl}$ and 15 sodium citrate, $\mathrm{pH} 7.0$, room temperature), $2 \times \mathrm{SSC}$ containing $50 \%$ formamide $\left(50^{\circ} \mathrm{C}, 30 \mathrm{~min}\right), 2 \times$ SSC $\left(37^{\circ} \mathrm{C}, 10 \mathrm{~min}\right), 2 \times$ SSC containing 20 $\mu \mathrm{g} / \mathrm{ml} \mathrm{RNase} \mathrm{A}\left(37^{\circ} \mathrm{C}, 30 \mathrm{~min}\right), 2 \times \operatorname{SSC}\left(37^{\circ} \mathrm{C}\right.$, $20 \mathrm{~min}$ ), and $0.1 \times$ SSC (room temperature, 30 and $5 \mathrm{~min}$ ). The hybridization signals were detected with the digoxigenin detection (Roche Diagnostics, Indianapolis, IN).

Antibodies. Rabbit and guinea pig polyclonal anti-a1803/CAPS2 and anti-CAPS1 antibodies were raised against the glutathione $S$-transferasetagged a1803/CAPS2 (amino acids 18-89 and 235-336) and CAPS1 (amino acids 18-107) that were bacterially expressed and were affinity-purified against the maltose binding protein-tagged antigenic proteins that were covalently coupled to cyanogen bromide-activated Sepharose 4B. Rabbit anti-a1803/CAPS2 (amino acids 18-89) and anti-CAPS1 (amino acids 18-107) antibodies were used for Western blotting, immunocytochemistry, and immunohistochemistry. Guinea pig anti-a1803/CAPS2 (amino acids 18-89) antibody was used for immunocytochemistry. The rabbit anti-a1803/ CAPS2 (amino acids 235-336) polyclonal antibody was used for immunoaffinity purification. The mouse anti-CAPS1 monoclonal antibody (BD Biosciences, Franklin Lakes, NJ) was also used for immunoaf- finity purification. The cross-reactivity of both antibodies was examined by exogenous cDNA expression experiments in PC12 cells; the antia1803/CAPS2 (amino acids 235-336) antibody weakly cross-reacted with the endogenous CAPS1 protein of PC12 cells, whereas the antiCAPS1 monoclonal antibody reacted with the endogenous CAPS1 of PC12 cells as indicated by the manufacturer but did not cross-react with the exogenously expressed CAPS2 protein. Anti-mouse polyclonal antivesicle-associated membrane protein (VAMP) antibody (StressGen Biotechnologies, San Diego, CA), mouse monoclonal anti-synaptophysin (Sigma, St. Louis, MO) and anti-chromogranin B (BD Biosciences) 

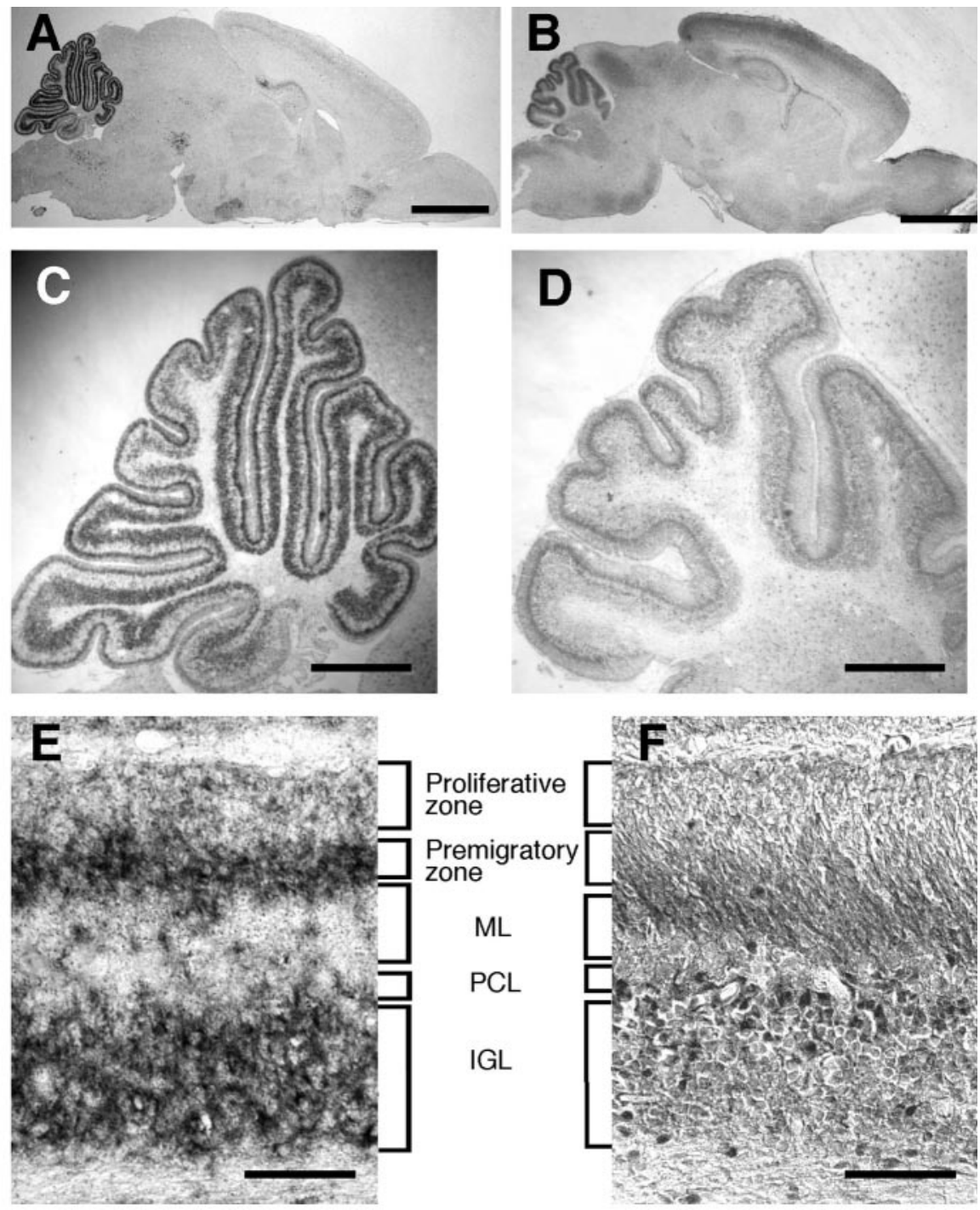

Figure 2. Expression of CAPS2 mRNA and protein in P7 mouse brains. $A, C, E$, In situ hybridization analysis of CAPS2 mRNA distribution in parasagittal brain sections: whole brain $(A)$, cerebellum $(C)$, and cerebellar cortex $(E)$ views. $B, D, F$, Immunohistochemical analysis of CAPS2 protein distribution in parasagittal brain sections: whole brain $(B)$, cerebellum $(D)$, and cerebellar cortex ( $F$ ) views. PCL, Purkinje cell layer. Scale bars: $A, B, 2 \mathrm{~mm} ; C, D, 500 \mu \mathrm{m} ; E, F, 50 \mu \mathrm{m}$.

antibodies, and rabbit anti-synaptotagmin I and II (Fukuda et al., 2002a) and anti-BDNF (Santa Cruz Biotechnologies, Santa Cruz, CA) antibodies were used for Western blotting. Mouse monoclonal anti-calbindin (Sigma), anti-MAP-2 (Roche Diagnostics), anti-postsynaptic density-95 (PSD-95; Sigma), and anti- $\alpha$-internexin (Chemicon, Temecula, CA) antibodies, rabbit anti-BDNF antibody (Katoh-Semba et al., 1997), and sheep anti-NT-3 antibody (Chemicon) were used for immunocytochemistry.

Immunoelectron microscopy. For immunoelectron microscopy of paraformaldehyde-fixed sections, mice (postnatal day 15 in Fig. 5A, $B$ and postnatal week 6 in Fig. $5 C$ ) were deeply anesthetized by ether and perfused with freshly prepared 2\% paraformaldehyde in PBS for 15 min. Brains were removed by dissection and cut with a razor into several coronal sections ( $\sim 2 \mathrm{~mm}$ thickness), which were soaked with the same fixative at $4^{\circ} \mathrm{C}$ for $2 \mathrm{hr}$. For cryoprotection, sections were placed into $20 \%$ sucrose solution for $2 \mathrm{hr}$ and $25 \%$ sucrose solution overnight. The sections were frozen using liquid nitrogen. Serial $10-\mu \mathrm{m}$-thick sections were cut in a cryostat. The samples were incubated with the rabbit polyclonal anti-CAPS2 antibody, followed by incubation with the anti-rabbit IgG antibody coupled with $1.4 \mathrm{~nm}$ gold particles (Nanoprobes Inc., Yaphank, NY). The sample-bound gold particles were silver-enhanced using an HQ-silver kit (Nanoprobes) at $18^{\circ} \mathrm{C}$ for $12 \mathrm{~min}$. The samples were again washed and postfixed with $0.5 \%$ osmium oxide in a buffer containing
$100 \mathrm{~mm}$ cacodylate buffer, $\mathrm{pH}$ 7.3. They were dehydrated by passage through a graded series of ethanol $(50,70,90$, and $100 \%)$ and propylene oxide and embedded in epoxy resin. From this sample, ultrathin sections were cut, stained with uranyl acetate and lead citrate, and then observed with an electron microscope (JEM1200EX; JEOL, Tokyo, Japan).

Subcellular fractionation. Homogenates of P21 mice cerebella were centrifuged at $100,000 \times g$ (Shiraishi et al., 1999), and the pellet fraction was further fractionated by centrifugation in continuous sucrose gradient from 0.3 to $1.8 \mathrm{M}$. After centrifugation, the subfractions were taken from the top (fraction 1) of the gradient to the bottom (fraction 16).

Immunoaffinity purification of cerebellar vesicle fractions. For immunoaffinity purification, $250 \mu \mathrm{g}$ of superparamagnetic polystyrene beads coated covalently with sheep anti-rabbit or anti-mouse IgG (Dynabeads M-280; Dynal, Lake Success, NY) were incubated overnight at $4^{\circ} \mathrm{C}$ in phosphate buffer (PBS, $\mathrm{pH} 7.4$, and $0.1 \%$ BSA) containing the primary antibody $(4 \mu \mathrm{g})$, rabbit anti-a1803/CAPS2 (amino acids 235-556) antibody, mouse anti-synaptophysin antibody, mouse anti-CAPS1 monoclonal antibody, and control rabbit IgG and mouse IgG (Jackson ImmunoResearch, West Grove, PA). P15 mouse cerebella were dissected and homogenized in low-sucrose homogenization buffer (in mm: 5 HEPES, pH 7.4, 5 EDTA, and 30 sucrose and protease inhibitor mixture). Homogenates were centrifuged at $800 \times g$ for $10 \mathrm{~min}$, and the crude membrane in the supernatant was incubated overnight with $500 \mu \mathrm{g}$ of the magnetic beads for preabsorption. The resultant supernatant-containing vesicle fractions were incubated with the primary antibody-bound beads in incubation buffer (PBS, pH 7.4, 5\% fetal bovine serum, and $2 \mathrm{~mm}$ EDTA) for $1 \mathrm{hr}$ at $4^{\circ} \mathrm{C}$. Vesicle-bound beads were collected and washed four times with incubation buffer and twice with PBS containing 2 mм EDTA for 15 min each. The collected vesicles were analyzed by ELISA or Western blotting.

CAPS2, NT-3, and BDNF expression plasmids. The mouse NT-3 and BDNF cDNA were subcloned into the pEF4/ Myc-His plasmid vector containing the EF- $1 \alpha$ promoter (Invitrogen). The a1803/CAPS2 cDNA was subcloned into the pcDNA3 plasmid vector containing the cytomegalovirus (CMV) promoter (Invitrogen) to create the pcDNA3-CAPS2 [wild type (wt)]. The pcDNA3-CAPS2 $(\Delta \mathrm{C} 2$ $+\mathrm{PH})$ had an internal deletion of amino acids 347-593, which corresponds to the $\mathrm{C} 2$ and pleckstrin homology $(\mathrm{PH})$ domain. The cDNA encoding the $\mathrm{C} 2$ and $\mathrm{PH}$ domain (amino acids 344-598) was subcloned into the pCMV-hemagglutinin (HA) plasmid vector (Clontech, Palo Alto, CA) to create pCMV-HA-CAPS2 $(\mathrm{C} 2+\mathrm{PH})$, which expresses the HA-tagged C2 and PH domain of a1803/CAPS2.

Preparation and infection of recombinant adenoviruses. A replicationdeficient adenovirus (Ad-CAPS2) was generated by the cosmidadenovirus terminal protein complex method (Miyake et al., 1996). Briefly, the full-length a1803/CAPS2 cDNA was inserted into the CAG promoter expression unit of pAxCAwt cosmid cassette (Takara Bio, Otsu, Shiga, Japan). Recombinant viruses were generated by homologous recombination between EcoT22I-digested Ad5-dlx DNA-terminal protein complex and recombinant cosmid vectors in human embryonic kidney 293 (HEK293) cells. The generated recombinant adenoviruses were propagated in HEK293 cells and then concentrated and purified by 
double-CsCl step gradient centrifugation. The virus titers were measured on HEK293 cells. The resulting Ad-CAPS2 was used for infection of primary cerebellar cultures (Shiraishi et al., 1999) at a multiplicity of infection of 30 for $1 \mathrm{hr}$ at $37^{\circ} \mathrm{C}$.

Secretion assay. Twenty-four hours after transfection with the expression plasmids as described above using Lipofectamine 2000 reagent (Invitrogen, Rockville, MD), PC12 cells were incubated in a fresh assay medium (DMEM containing $0.2 \% \mathrm{BSA}$ ) for $30 \mathrm{~min}$ and then incubated in a fresh assay medium with or without (in $\mathrm{mm}$ ): $50 \mathrm{KCl}, 10 \mathrm{EGTA}$, or both for a further $5 \mathrm{~min}$. The control and high- $\mathrm{KCl} \mathrm{stim-}$ ulation assay media were collected and the neurotrophin contents secreted were measured with an NT-3/BDNF Emax immunoassay system (Promega, Madison, WI) according to the manufacturer's instructions. When using modified HBSS ( $125 \mathrm{~mm} \mathrm{NaCl}, 5 \mathrm{~mm} \mathrm{KCl}, 1.2 \mathrm{~mm}$ $\mathrm{NaH}_{2} \mathrm{PO}_{4}, 1.2 \mathrm{~mm} \mathrm{MgCl}, 1 \mathrm{~mm} \mathrm{CaCl}, 1 \mu \mathrm{M}$ $\mathrm{ZnCl}_{2}, 10 \mathrm{~mm}$ glucose, $25 \mathrm{~mm}$ HEPES, and $0.2 \%$ BSA, pH 7.4) instead of DMEM, similar results were obtained by stimulating with the modified HBSS containing (in mM): $50 \mathrm{KCl}$ and $80 \mathrm{NaCl}$. A secretion assay for cerebellar cultures was performed with medium incubated for $15 \mathrm{~min}$.

\section{Results}

Differential developmental and cellular expression of CAPS 2 in mouse cerebellum

To examine the genetic basis of mouse cerebellar development, we analyzed the developmental stage-specific gene expression using a differential display technique (Shiraishi et al., 1999) and isolated a developmentally regulated clone, a1803, with the expression peak at $\sim$ P12 (Fig. 1A), when various cellular developmental events are actively occurring, e.g., immense cell proliferation and migration and vigorous genesis of axons, dendrites, and synapses. Tissue distribution analysis of adult (P56) mice by reverse transcription (RT)-PCR showed that a1803 expression predominates in the cerebellum within the CNS and is detected at low levels in nonneuronal tissues, including lung, spleen, testis, uterus, and ovary (Fig. $1 B$ ). A predicted a1803 protein has structural features similar to the $\mathrm{C} 2$ and $\mathrm{PH}$ domains and the Munc13-1-homologous domain (MHD) containing a syntaxin-interacting domain (Fig. $1 C$ ) and shares $70.4 \%$ amino acid identity with CAPS, which is essential for $\mathrm{Ca}^{2+}$-triggered SG exocytosis in permeabilized PC12 cells (Walent et al., 1992; Berwin et al., 1998; Tandon et al., 1998), as shown in Figure $1 D$. An open reading frame of mouse CAPS2 cDNA that has recently been registered on the public DNA database differs from that of a1803; there are two different stretches in either sequence, which probably results from alternative splicing events (Fig. 1D). Hereafter, if necessary, the a1803 splicing form is depicted as a1803/CAPS2 or CAPS2a, whereas the other CAPS2 variant is called CAPS2b. The original CAPS is called CAPS1. The RT-PCR analysis using the primers specific to the $5^{\prime}$-splicing segment showed that the mRNA for the a1803/ CAPS2a splicing form containing the 5 '-splicing segment was highly expressed in the postnatal and adult stages of the cerebellum, whereas that for CAPS2b lacking the 5 '-splicing segment was undetectable (data not shown), indicating that the a1803/CAPS2a is the predominant form in the mouse cerebellum.

\section{CAPS2 is located in presynaptic parallel fiber terminals of granule cells}

In situ hybridization analyses showed that in $\mathrm{P} 7$ mouse brains, the CAPS2 mRNA was predominantly expressed in the cerebellum (Fig. 2A) in which the postmitotic premigratory zone of the external granule layer (EGL) and the internal granule layer (IGL) were the predominant sites (Fig. 2C,E), indicating that CAPS2 is specific to differentiating and differentiated granule cells. In P21 brains, mRNA expression was detected at the highest level in cerebellar granule cells (Fig. $3 A, C, F$ ) and at lower levels in the hippocampal region and interpeduncular nucleus (Fig. $3 A$ ). Immunohistochemical analyses showed the predominant distribution of CAPS2 protein in the cerebellum at P7 (Fig. $2 B, D, F$ ) and P21 (Fig. $3 B, D, G$ ). In P21 cerebella, it was a marked contrast that the mRNA and protein were respectively localized to the IGL (Fig. $3 F$ ) and the molecular layer (ML) (Fig. 3G), indicating that the protein subcellularly distributes in granule cell axons (PFs). On the contrary, CAPS1 distributed over the whole brain area (data not shown). In the cerebellum, the CAPS1 mRNA was expressed in the IGL (data not shown), and the protein was located in glomerular rosettes of the IGL at a high level and Purkinje cells at a low level (Fig. $3 E, H$ ). These results indicate that CAPS2 and CAPS1 occupy distinct cellular distributions in the cerebellum.

We analyzed the subcellular localization of CAPS2 protein using cerebellar primary cultures at $14 \mathrm{~d}$ in vitro (DIV) (Fig. 4). 

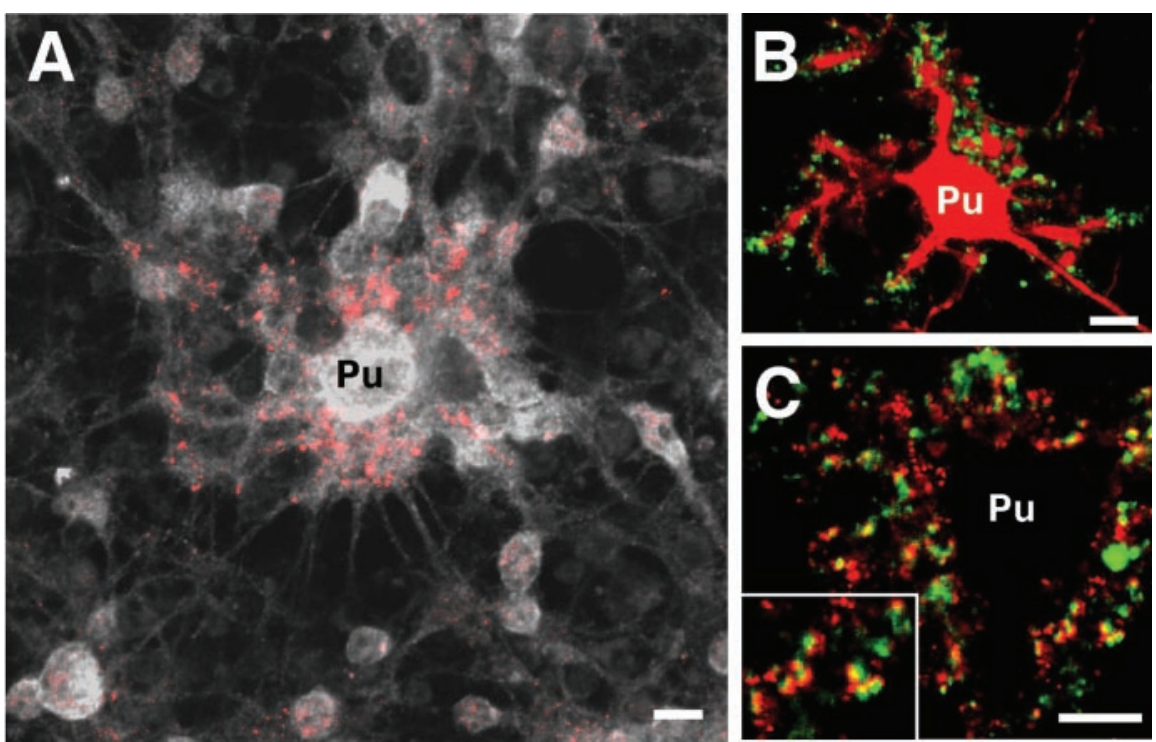

Figure 4. Subcellular localization of CAPS2 protein in cerebellar granule cells. A, Fluorescent confocal images of cerebellar cultures (14 DIV) immunostained with the anti-CAPS2 (red) and anti- $\alpha$-internexin (white) antibodies. $B$, Fluorescent confocal images of cerebellar cultures (14 DIV) immunostained with the anti-CAPS2 (green) and anti-calbindin (red) antibodies. C, Fluorescent confocal images of cerebellar cultures (14 DIV) immunostained with the anti-CAPS2 (green) and anti-PSD-95 (red) antibodies. Inset, Higher magnification. Pu, Purkinje cell. Scale bars, $10 \mu \mathrm{m}$.
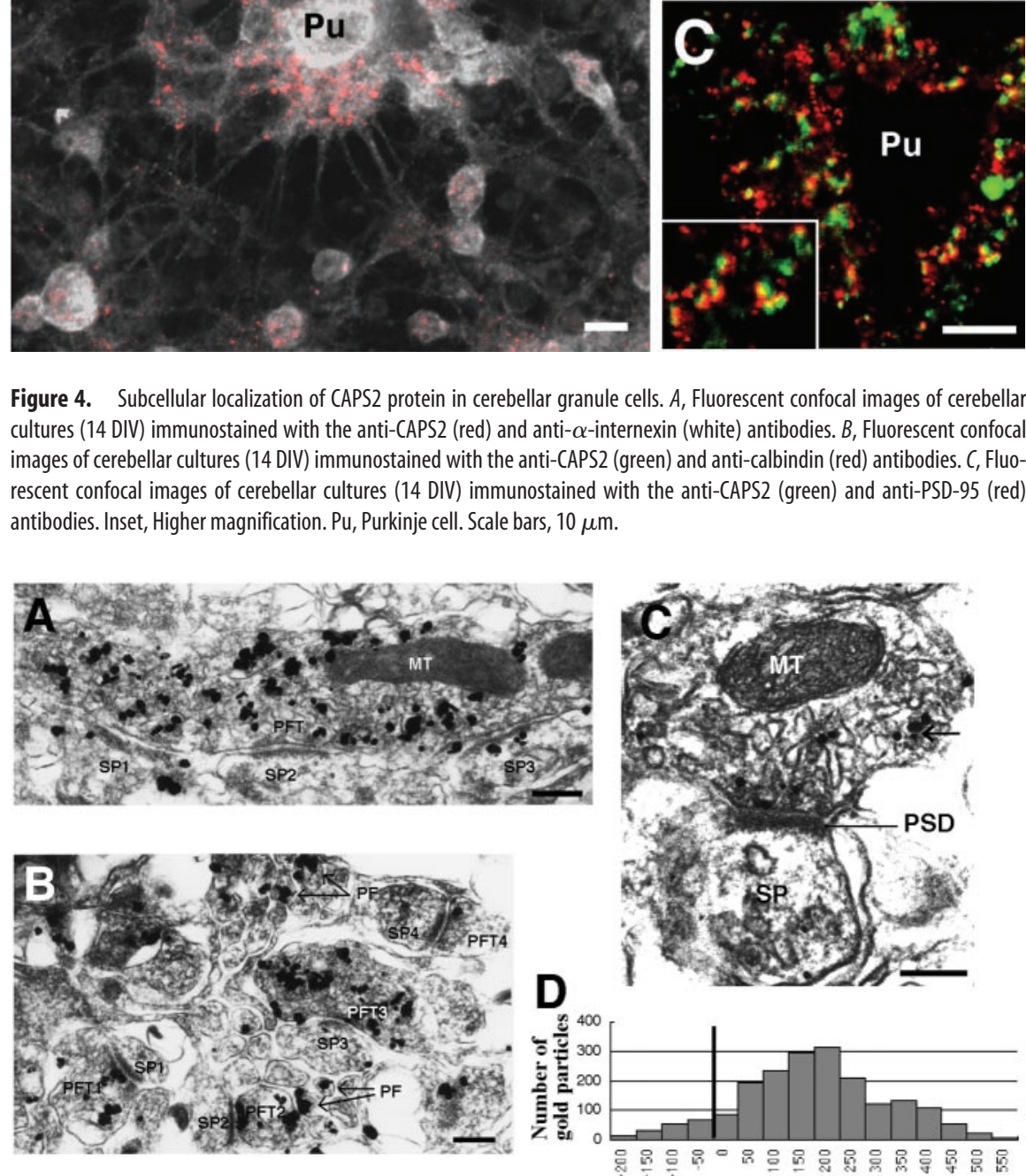

Figure 5. Immunoelectron microscopic study of the CAPS2 protein in the mouse cerebellum. $A, B$, Electron micrographs of the molecular layer in the P15 mouse cerebellar coronal section $(A)$ and sagittal section $(B)$ reacted with the immunogold of antiCAPS2 antibody. CAPS2 immunogold particles were predominantly detected in vesicular structures and were also present near the presynaptic and perisynaptic membranes and in spines. MT, Mitochondrion. C, Electron micrographs of the molecular layer of a 6-week-old mouse cerebellum reacted with the immunogold of anti-CAPS2 antibody. Extrasynaptic localization of immunogold particles apart from the active zone is indicated by an arrow. D, Quantification of CAPS2 distribution on the electron micrographs. The distance between CAPS2 immunogold particles and the active zone (position 0) was examined by calculating of 160 synapses in P15 cerebellar sagittal sections. The distance between immunogold particles and the active zone is indicated on the $x$-axis; numbers of immunogold particles are represented on the $y$-axis. +, Presynaptic side; -,postsynaptic side. Distribution of CAPS2 immunogold particles peaked at a presynaptic site $250 \mathrm{~nm}$ distant from the active zone. Scale bars, $200 \mathrm{~nm}$.

Punctate immunoreactivity of CAPS2 was primarily concentrated near Purkinje cells innervated by many granule cell axons immunostained for $\alpha$-internexin (Chien et al., 1996) (Fig. 4A). Coimmunostaining for calbindin, a marker for Purkinje cells, showed that the CAPS2 puncta clustered around the dendrites of Purkinje cells (Fig. $4 B$ ). In addition, coimmunostaining for PSD95, a marker for postsynapses, showed that the puncta of CAPS2 $\mathrm{nm}$

were located near those of PSD-95, which immunostained the postsynaptic spines of Purkinje cells (Fig. 4C), suggesting the presynaptic localization of CAPS2 in PFs. To confirm this, we performed an immunogold electron microscopic observation (Fig. 5). In coronal sections of the P15 mouse cerebellum (longitudinal views of PFs) (Fig. 5A), immunogold particles for CAPS2 were predominantly distributed on vesicular structures in parallel fiber terminals (PFTs) connecting multiple spines (SP1-3, called en passant synapses), which are characteristic to the cerebellar PFTs, and were also present near the presynaptic (active zone) and perisynaptic membrane and spines. In sagittal sections of the P15 mouse cerebellum (transverse views of PFs; (Fig. 5B), CAPS2 immunogold particles were predominantly localized on vesicular structures and also detectable near the presynaptic (PFT1 and 3) and perisynaptic (PFT2 and 3) membrane and on postsynapses (SP3). In addition, CAPS2 immunogold particles were observed in transverse PFs. In 6-week-old mouse cerebella (Fig. 5C), CAPS2 immunogold particles were concentrated at the PFTs connecting dendritic spines of Purkinje cells and were detected on vesicular structures and in regions around the active zone and extrasynaptic sites. Distribution of CAPS2 was quantified by calculating the numbers of CAPS2 immunogold particles in $160 \mathrm{PF}$ $\rightarrow$ Purkinje cell synapses as a function of the distance from the active zone (Fig. 5D). As a result, CAPS2 was primarily distributed at presynaptic sites $250 \mathrm{~nm}$ distant from the active zone, which corresponded to the interval of five standard synaptic vesicles. It is noteworthy that there was significant CAPS2 distribution near the active zone (Fig. $5 D, 0$ to $+50 \mathrm{~nm}$ ).

\section{CAPS2 is associated with vesicles distinct from synaptic vesicles}

It was previously shown that CAPS1 associates with purified plasma membranes and SGs of rat brains (Berwin et al., 1998) and is essential for $\mathrm{Ca}^{2+}$-triggered SG exocytosis in permeabilized PC12 cells (Tandon et al., 1998). A Drosophila mutant lacking a CAPS ortholog (dCAPS) was used to show that dCAPS is required for SG exocytosis in neuromuscular junctions (Renden et al., 2001). To examine the property of subcellular fraction containing CAPS2, a crude synaptosomal P2 fraction was prepared from P21 mouse cerebella and further fractionated by floatation in continuous gradients of $0.3-1.8 \mathrm{M}$ sucrose. In Figure $6 \mathrm{~A}$, Western blotting analyses of the resultant subfractions showed that immunoreactivity to an SV marker, synaptophysin (Syph), was recovered in lower-density fractions (fractions 2-4, from top to bottom), whereas that to a 


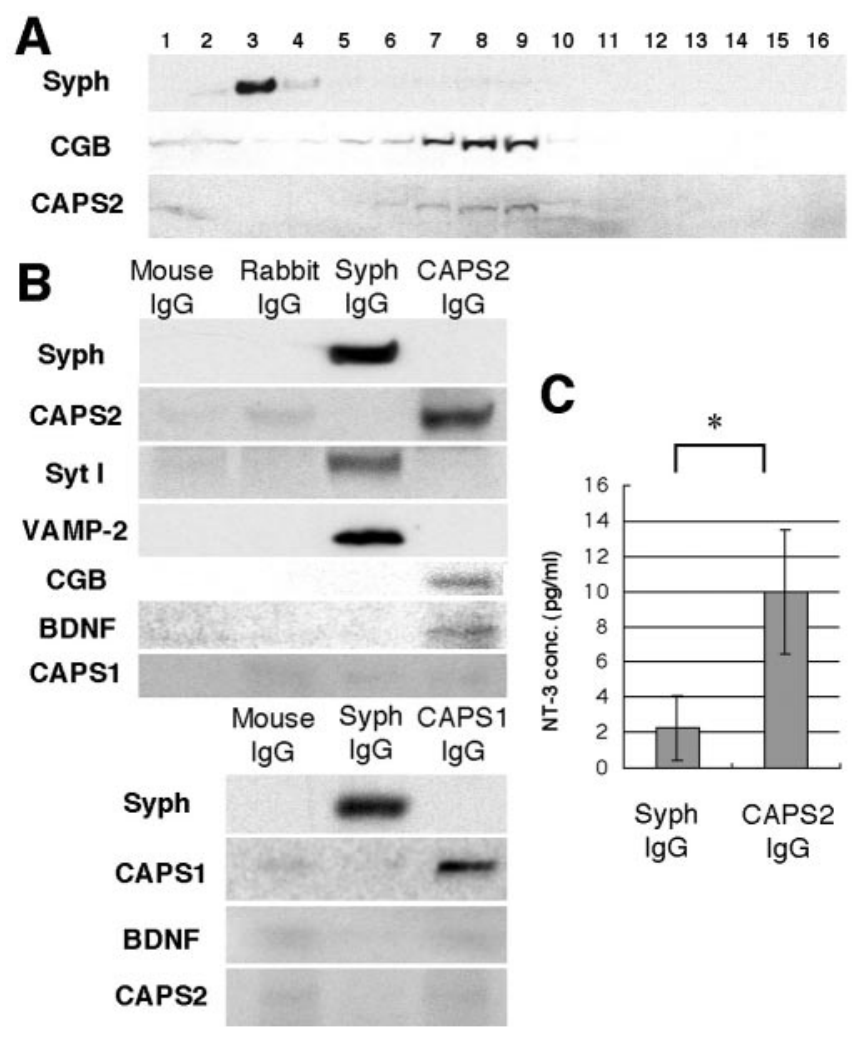

Figure 6. Characterization of CAPS2-associated vesicular fractions. A, Western blotting analysis of subcellular vesicular fractions prepared from P21 mouse cerebella. The subfractions separated by $0.3-1.8 \mathrm{~m}$ sucrose gradient centrifugation were taken from the top (fraction 1) to the bottom (fraction 16). Each fraction was analyzed for immunoreactivity Syph, CGB, and CAPS2.B, Western blotting analysis of vesicle fractions that were immunoaffinity-purified using magnetic beads coated with the control mouse lgG, control rabbit lgG, anti-Syph antibody, and anti-CAPS2 antibody from P15 mouse cerebella. Each immunopurified fraction was analyzed for immunoreactivity to Syph, CAPS2, Syt I, VAMP-2, CGB, and BDNF. A vesicle fractions that was immunoaffinity-purified with anti-CAPS1 antibody was also analyzed for the content of synaptophysin, CAPS1, BDNF, and CAPS2. C, Sensitive two-site enzyme immunoassay for NT-3 in the Syph- and CAPS2-immunopurified vesicles. Each value represents mean \pm SD from four independent experiments. ${ }^{*} p<0.02$.

SG marker CGB was in higher-density fractions (fractions 7-9) in which immunoreactivity of CAPS2 was cofractionated.

To further characterize each fraction, we purified vesicular fractions from P15 mouse cerebella by affinity for the antibodycoated magnetic beads (rabbit anti-CAPS2 IgG and control rabbit IgG and mouse anti-Syph IgG and control mouse IgG) and analyzed their protein components by Western blotting (Fig. $6 B)$. The vesicular fraction immunopurified with the anti-Syph beads (Syph vesicle) contained SV proteins synaptotagmin (Syt) I (Fig. 6B) and II (data not shown) other than Syph, whereas that with the anti-CAPS2 beads (CAPS2-vesicle) was completely negative to such SV markers (Fig. 6B). A vesicle-associated membrane protein, VAMP-2, was present in the Syph vesicle (Fig. $6 B$ ). The presence of VAMP-2 in SGs is not definitive yet: present at a low level in SGs from chromaffin cells (Winkler, 1997) versus absent in SGs from rat brains (Zhai et al., 2001). In the CAPS2 vesicle, no trace amount of VAMP-2 was observed (Fig. 6B). Moreover, CGB was included in the CAPS2 vesicle but not in the Syph vesicle. Another SG protein, chromogranin A (CGA), was not detected in the CAPS2 vesicle (data not shown). Interestingly, there was no trace amount of CAPS1 detectable by this blot (Fig. $6 B)$, although the anti-CAPS2 antibody used for this immunobead weakly cross-reacted with the CAPS1 protein (see Materials and Methods), again indicating the predominant expression of CAPS2 in the cerebellum, as shown in Figure 3, $G$ and $H$. Together, these results indicate that the Syph vesicle and the CAPS2 vesicle are molecularly separable.

\section{CAPS2-associated vesicles contain neurotrophins}

The Syph vesicle could be for neurotransmitters, e.g., glutamate and GABA, in the cerebellum. This raises the question of what the CAPS2 vesicle is. We examined various candidates that are known secretory substances produced by granule cells and found that the CAPS2 vesicle contains BDNF and NT-3, which are important neurotrophins for cerebellar development and maintenance. Western blotting for BDNF showed that only the CAPS2 vesicle had apparent immunoreactivity to a $14 \mathrm{kDa}$ band corresponding to BDNF (Fig. 6B). We could not detect NT-3 by this Western blotting, which was probably attributable to its amount, the detection limit of the anti-NT-3 antibody we used, or both. However, using the highly sensitive two-site enzyme immunoassay (Katoh-Semba et al., 2000), we were able to detect significant amounts of NT-3 in the CAPS2 vesicle but not in the Syph vesicle (Fig. 6C). These results indicate that CAPS2 is associated with vesicles containing BDNF and NT-3, which are separable from typical SVs. On the contrary, the immunoisolated vesicle with anti-CAPS1 monoclonal antibody, which did not cross-react with the CAPS2 protein, and did not contain BDNF, CAPS2 (Fig. $6 B$ ), or NT-3 (data not shown).

To ascertain the coincidence in subcellular localization between CAPS2 and neurotrophins, we conducted immunocytochemical analyses of cultured cerebellar neurons (14 DIV) (Fig. 7). Most immunoreactive puncta of CAPS2 were primarily colocalized with those of NT-3 (Fig. 7A-C) and of BDNF (Fig. 7D-F) in regions surrounding dendritic arborizations of Purkinje cells.

\section{CAPS2 has activity to enhance depolarization-induced release} of neurotrophins

To investigate the functional role of CAPS2, we heterologously expressed the CAPS2 constructs together with NT-3 or BDNF in PC1 2 cells and analyzed NT-3 or BDNF secretion by ELISA. PC12 cells express CAPS1 but not CAPS2, NT-3, or BDNF. As shown in Figure $8, A$ and $B$, by expressing NT-3 or BDNF in PC1 2 cells, the immunoreactivity for NT-3 or BDNF in the culture media was slightly increased without stimulation, which may be via a constitutive secretion pathway or may be stimulated by unknown factors under the present culture conditions. On high-KCl stimulation, immunoreactivity was increased approximately twofold (for NT-3) (Fig. 8A) and fourfold (for BDNF) (Fig. $8 B$ ) from the basal levels, which is consistent with previous reports describing the depolarization-dependent secretion of exogenously expressed BDNF (Goodman et al., 1996) and NT-3 (Heymach et al., 1996) in PC12 cells probably via CAPS1. By coexpressing the full-length CAPS2 (wt), the high-KCl-induced immunoreactivity to NT-3 and BDNF was enhanced $\sim 2$ - and 1.7-fold, respectively, compared with expressing NT-3 or BDNF alone. This CAPS2mediated enhancement of NT-3 and BDNF immunoreactivity in culture media depended on high-KCl stimulation, and extracellular EGTA in the presence of high $\mathrm{KCl}$ blocked this enhancement, suggesting the importance of membrane depolarizationinduced $\mathrm{Ca}^{2+}$ influx, which is generally elicited by high- $\mathrm{KCl}$ stimulation. On the other hand, coexpression of the CAPS2 mutant carrying the $\mathrm{C} 2$ and $\mathrm{PH}$ domain alone $(\mathrm{C} 2+\mathrm{PH})$ or lacking the $\mathrm{C} 2$ and $\mathrm{PH}$ domain $(\Delta \mathrm{C} 2+\mathrm{PH})$ did not confer this enhancement, indicating the importance of these structural domains for this activity. 

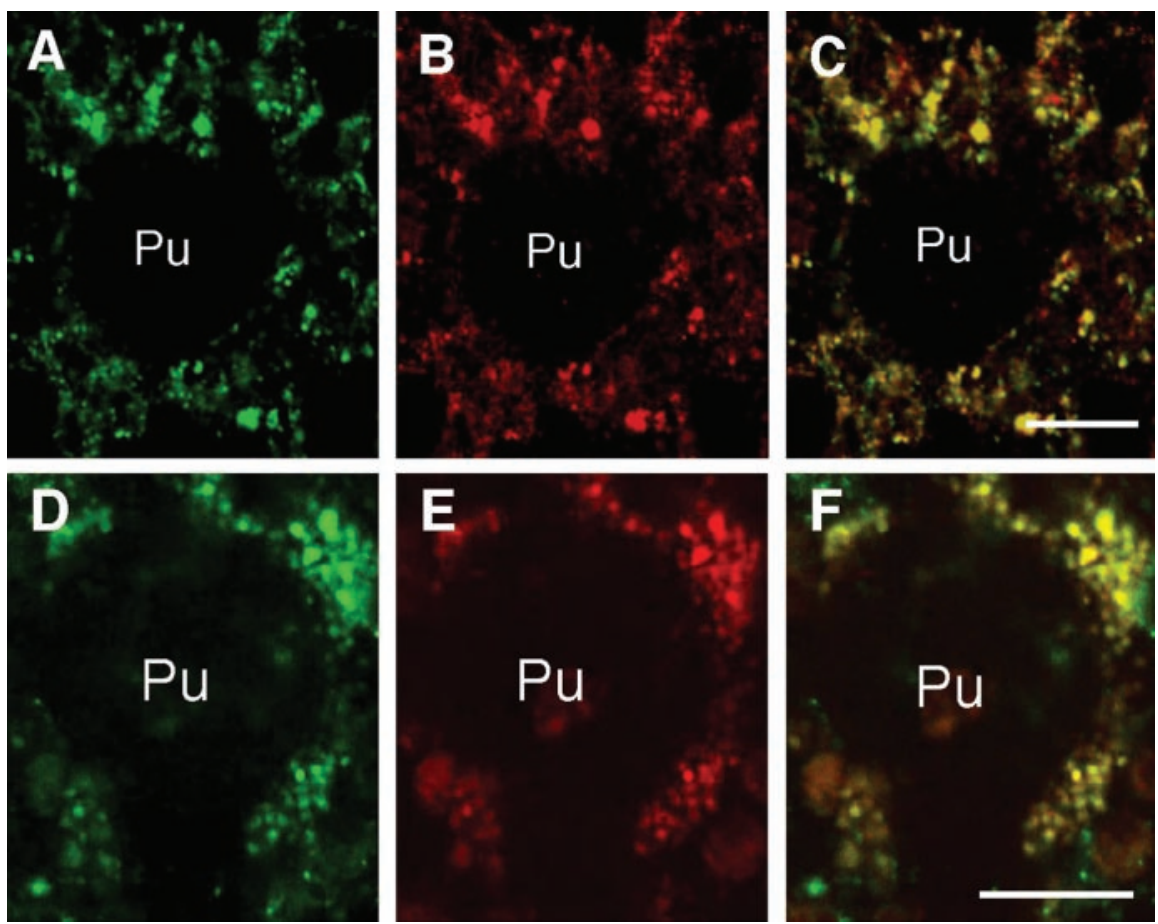

Figure 7. Colocalization of CAPS2, NT3, and BDNF in cerebellar cultures at 14 DIV. $A-C$, Confocal fluorescent images of cerebellar neurons immunostained with the anti-CAPS2 $(A$, green) and anti-NT-3 $(B$, red) antibodies. D-F, Confocal fluorescent images of cerebellar neurons immunostained with the anti-CAPS2 ( $D$, green) and anti-BDNF ( $E$, red) antibodies. $C, F$, Merged images between $A, B$ and $D, E$, respectively. Pu, Purkinje cell. Scale bars, $10 \mu \mathrm{m}$.
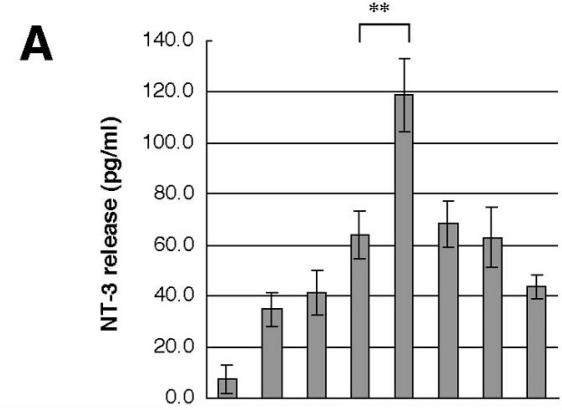

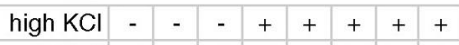

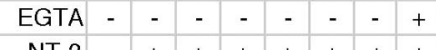

NT-3

CAPS2(wt)

CAPS2 $(\mathrm{C} 2+\mathrm{PH})$

$\mathrm{CAPS} 2(\triangle \mathrm{C} 2+\mathrm{PH})$

Figure 8. Enhanced release of NT-3 and BDNF by exogenously expressed CAPS2 from PC12 cells. PC12 cells were transfected with the CAPS2 constructs (wt, $\mathrm{C} 2+\mathrm{PH}, \triangle \mathrm{C} 2+\mathrm{PH}$; see Materials and Methods) together with NT-3 $(A)$ or BDNF $(B)$, and the amounts of NT-3 $(A)$ and $B D N F(B)$ released into the culture media with or without $50 \mathrm{~mm} \mathrm{KCl} \mathrm{stimulation} \mathrm{were} \mathrm{analyzed} \mathrm{by} \mathrm{ELISA.}$ Data points represent the average of values obtained from three independent experiments $\pm S D{ }^{* *} p<0.01$.
B

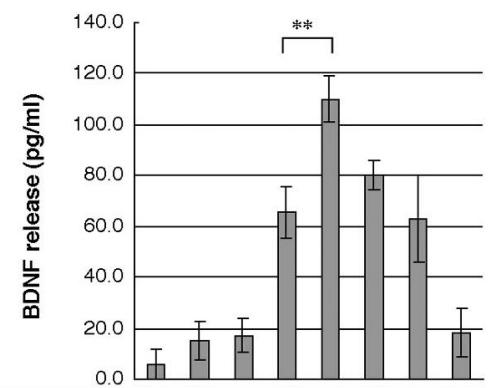

high $\mathrm{KCl}$

EGTA

BDNF

CAPS2(wt)

CAPS2 $(\mathrm{C} 2+\mathrm{PH})$

CAPS2 $(\triangle \mathrm{C} 2+\mathrm{PH})$

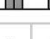

-

$-\quad+$

$+-+$

$\begin{array}{ll}- & + \\ - & -\end{array}$

- + 
and Purkinje cell development, which are modulated by both NT-3 and BDNF (Lindholm et al., 1993; Segal et al., 1995; Lindholm et al., 1997; Schwartz et al., 1997; Doughty et al., 1998; Bates et al., 1999).

CAPS2 is involved in activity-dependent neurotrophin release from neurons We showed that CAPS2 and CAPS1 are differentially distributed in mouse cerebellum; the former predominates at the PF terminals in the ML, whereas the latter is preferentially located at the glomeruli in the IGL, indicating their differential cellular function in the cerebellum. CAPS1 is known to regulate $\mathrm{Ca}^{2+}$-dependent release of $\left[{ }^{3} \mathrm{H}\right]$ norepinephrine from the preloaded PC12 cells (Ann et al., 1997) and rat brain synaptosomes (Berwin et al., 1998; Tandon et al., 1998). CAPS2 might control the release of such catecholamines. However, cerebellar granule cells express neither tyrosine hydroxylase, the first enzymatic step in catecholamine synthesis (Austin et al., 1992; Takada et al., 1993), nor dopamine- $\beta$-hydroxylase (Verney et al., 1982), indicating that CAPS2 is involved in the release of substances, except for catecholamines, in the vesicles of PF terminals. We then showed that exogenously expressed CAPS2 promotes the NT-3 and BDNF release from PC12 cells and NT-3 release from granule cells in a depolarization-dependent manner. Substances released by CAPS1 in cerebellar glomeruli remain elusive.

BDNF and NT-3 are released in an activity-dependent manner (Goodman et al., 1996; Heymach et al., 1996; Kohara et al., 2001) and regulate their own secretion (Canossa et al., 1997; Kruttgen et al., 1998). However, little research into the molecules involved in the neurotrophin release from neurons has been reported (Canossa et al., 2001; Balkowiec and Katz, 2002; Wang et al., 2002). Thus, the present finding provides a clue to elucidating the underlying molecular basis.

\section{CAPS2-associated vesicles within the PF fiber terminals are distinct from synaptic vesicles}

We found CAPS2 in vesicular and membranous structures in the PF terminals. The purified CAPS2 vesicles contain BDNF and NT-3, an SG marker CGB, but did not contain another SG marker, CGA, and SV markers Syt I and II and VAMP-2, indicating that the CAPS2 vesicles are completely separated from typical SVs. CGA is a key regulator of dense-core SG biosynthesis in PC12 cells, but CGB is not (Corradi et al., 1996; Kim et al., 2001). Our electron micrographs of PF terminals (Fig. 5A-C) revealed no apparent dense-core-like vesicles as previously reported (Carter et al., 2002), indicating that CAPS2 vesicles of the PF terminals are probably different from typical dense-core vesicles. This feature in the molecular composition and electron microscopic view is likely consistent with the fact that CGB does not play a direct role in dense-core SG biogenesis in PC12 cells (Corradi et al., 1996; Kim et al., 2001). On the contrary, the presence of NT-3 and BDNF in large dense-core SGs has been reported in the retinotectal terminals of chicken embryos (Wang et al., 2002) and the axonal terminals of rat dorsal root ganglions (Michael et al.,
1997), respectively. Cerebellar granule cells, although they express BDNF and NT-3, do not express CGA mRNAs (Mahata et al., 1991). Thus, the biochemical properties and electron microscopic view of vesicles containing neurotrophins appear different from cell type to cell type.

In SV exocytosis, a variety of molecules are involved in a series of stages (Jahn and Sudhof, 1999; Chen and Scheller, 2001; Rettig and Neher, 2002). On the other hand, the detailed molecular mechanism underlying SG exocytosis remains to be studied (Haynes et al., 2001; Voets et al., 2001a,b; Fukuda et al., 2002b; Shin et al., 2002). CAPS2 contains a predicted C2 domain, as does CAPS1, and enhances the NT-3 and BDNF release by stimulation with high $\mathrm{KCl}$, which generally elicits membrane depolarization leading to $\mathrm{Ca}^{2+}$ influx. How CAPS2 functions in the vesicle exocytosis remains to be studied. In addition, to understand its underlying molecular machinery, CAPS2-related molecules require elucidation.

\section{A role of CAPS2-mediated neurotrophin release in cerebellar development}

During postnatal development, the mouse cerebellum undergoes a series of magnificent cellular events to accomplish the formation of a functional circuit and architecture. Granule cells are generated by vigorous cell proliferation in the EGL to reach an immense cell number of approximately half the neurons in the brain, extend their PF axons, and migrate downward to form the IGL. Purkinje cells undergo robust outgrowth of dendrites and form elaborate arborization with numerous synapses with extending PFs of granule cells. During this period, neurotrophins act as important modulators for differentiation and survival of cerebellar neurons (Lindholm et al., 1993, 1997; Segal et al., 1995; Schwartz et al., 1997; Doughty et al., 1998; Bates et al., 1999). Among them, NT-3 and BDNF are closely related to the interaction between granule cells and Purkinje cells. Mice genetically deficient in the genes of these neurotrophins showed abnormal 
cerebellar morphology (Schwartz et al., 1997; Bates et al., 1999). We showed that the exogenous CAPS2 overexpression promotes the Purkinje cell survival as the result of an increase in the neurotrophin release activity from granule cells. In our culture system (7-10 Purkinje cells per $10^{5}$ plating cells), Purkinje cells were more susceptible to cell death than granule cells, and their survival primarily depended on the numbers of granule cells or astrocytes (Yuzaki and Mikoshiba, 1992). Effects on granule cell viability, neuronal differentiation, including neurite outgrowth and synapse formation, or both would be expected to be seen by use of appropriate systems such as granule cell cultures at low cell density or in low-KCl medium and genetically manipulated animal models.

In contrast to the predominant localization of CAPS2 to the PF terminals, CAPS1 distributes specifically in glomerular rosettes in the cerebellum and is widespread in other brain areas. The present study suggests that CAPS1 and CAPS2 share their roles in modulation of cerebellar development and function, although what kinds of substances, including, e.g., neurotrophins and neuropeptide, are released by CAPS1 should be examined, and CAPS2 is specifically associated with the cerebellar postnatal development during which tens of millions of neurons undergo vigorous differentiation events. Moreover, CAPS2-mediated BDNF release may be involved in synaptic plasticity even in the fully developed cerebellar circuitry, because BDNF has a modulatory role in the short-term plasticity of $\mathrm{PF} \rightarrow$ Purkinje cell synapses (Carter et al., 2002).

\section{References}

Ann K, Kowalchyk JA, Loyet KM, Martin TF (1997) Novel Ca ${ }^{2+}$-binding protein (CAPS) related to UNC-31 required for $\mathrm{Ca}^{2+}$-activated exocytosis. J Biol Chem 272:19637-19640.

Austin MC, Schultzberg M, Abbott LC, Montpied P, Evers JR, Paul SM, Crawley JN (1992) Expression of tyrosine hydroxylase in cerebellar Purkinje neurons of the mutant tottering and leaner mouse. Brain Res Mol Brain Res 15:227-240.

Balkowiec A, Katz DM (2002) Cellular mechanisms regulating activitydependent release of native brain-derived neurotrophic factor from hippocampal neurons. J Neurosci 22:10399-10407.

Bates B, Rios M, Trumpp A, Chen C, Fan G, Bishop JM, Jaenisch R (1999) Neurotrophin-3 is required for proper cerebellar development. Nat Neurosci 2:115-117.

Berwin B, Floor E, Martin TF (1998) CAPS (mammalian UNC-31) protein localizes to membranes involved in dense-core vesicle exocytosis. Neuron 21:137-145.

Canossa M, Griesbeck O, Berninger B, Campana G, Kolbeck R, Thoenen H (1997) Neurotrophin release by neurotrophins: implications for activitydependent neuronal plasticity. Proc Natl Acad Sci USA 94:13279-13286.

Canossa M, Gartner A, Campana G, Inagaki N, Thoenen H (2001) Regulated secretion of neurotrophins by metabotropic glutamate group I (mGluRI) and Trk receptor activation is mediated via phospholipase C signaling pathways. EMBO J 20:1640-1650.

Carter AR, Chen C, Schwartz PM, Segal RA (2002) Brain-derived neurotrophic factor modulates cerebellar plasticity and synaptic ultrastructure. J Neurosci 22:1316-1327.

Chen YA, Scheller RH (2001) SNARE-mediated membrane fusion. Nat Rev Mol Cell Biol 2:98-106.

Chien CL, Mason CA, Liem RK (1996) Alpha-internexin is the only neuronal intermediate filament expressed in developing cerebellar granule neurons. J Neurobiol 29:304-318.

Corradi N, Borgonovo B, Clementi E, Bassetti M, Racchetti G, Consalez GG, Huttner WB, Meldolesi J, Rosa P (1996) Overall lack of regulated secretion in a PC12 variant cell clone. J Biol Chem 271:27116-27124.

Das KP, Chao SL, White LD, Haines WT, Harry GJ, Tilson HA, Barone Jr S (2001) Differential patterns of nerve growth factor, brain-derived neurotrophic factor and neurotrophin-3 mRNA and protein levels in developing regions of rat brain. Neuroscience 103:739-761.

Doughty ML, Lohof A, Campana A, Delhaye-Bouchaud N, Mariani J (1998)
Neurotrophin-3 promotes cerebellar granule cell exit from the EGL. Eur J Neurosci 10:3007-3011.

Egan MF, Kojima M, Callicott JH, Goldberg TE, Kolachana BS, Bertolino A, Zaitsev E, Gold B, Goldman D, Dean M, Lu B, Weinberger DR (2003) The BDNF val66met polymorphism affects activity-dependent secretion of BDNF and human memory and hippocampal function. Cell 112:257-269.

Fukuda M, Kowalchyk JA, Zhang X, Martin TF, Mikoshiba K (2002a) Synaptotagmin IX regulates $\mathrm{Ca}^{2+}$-dependent secretion in PC12 cells. J Biol Chem 277:4601-4604.

Fukuda M, Kanno E, Saegusa C, Ogata Y, Kuroda TS (2002b) Slp4-a/ granuphilin-a regulates dense-core vesicle exocytosis in PC12 cells. J Biol Chem 277:39673-39678.

Gao WQ, Zheng JL, Karihaloo M (1995) Neurotrophin-4/5 (NT-4/5) and brain-derived neurotrophic factor (BDNF) act at later stages of cerebellar granule cell differentiation. J Neurosci 15:2656-2667.

Ginty DD, Segal RA (2002) Retrograde neurotrophin signaling: Trk-ing along the axon. Curr Opin Neurobiol 12:268-274.

Goodman LJ, Valverde J, Lim F, Geschwind MD, Federoff HJ, Geller AI, Hefti F (1996) Regulated release and polarized localization of brain-derived neurotrophic factor in hippocampal neurons. Mol Cell Neurosci 7:222-238.

Haynes LP, Evans GJ, Morgan A, Burgoyne RD (2001) A direct inhibitory role for the Rab3-specific effector, Noc2, in $\mathrm{Ca}^{2+}$-regulated exocytosis in neuroendocrine cells. J Biol Chem 76:9726-9732.

Heymach Jr JV, Kruttgen A, Suter U, Shooter EM (1996) The regulated secretion and vectorial targeting of neurotrophins in neuroendocrine and epithelial cells. J Biol Chem 271:25430-25437.

Horch HW, Katz LC (2002) BDNF release from single cells elicits local dendritic growth in nearby neurons. Nat Neurosci 5:1177-1184.

Huang EJ, Reichardt LF (2002) Neurotrophins: roles in neuronal development and function. Annu Rev Neurosci 24:677-736.

Jahn R, Sudhof TC (1999) Membrane fusion and exocytosis. Annu Rev Biochem 68:863-911.

Katoh-Semba R, Takeuchi IK, Semba R, Kato K (1997) Distribution of brain-derived neurotrophic factor in rats and its changes with development in the brain. J Neurochem 69:34-42.

Katoh-Semba R, Takeuchi IK, Semba R, Kato K (2000) Neurotrophin-3 controls proliferation of granular precursors as well as survival of mature granule neurons in the developing rat cerebellum. J Neurochem 74:1923-1930.

Kim T, Tao-Cheng JH, Eiden LE, Loh YP (2001) Chromogranin A, an "on/ off" switch controlling dense-core secretory granule biogenesis. Cell 106:499-509.

Kohara K, Kitamura A, Morishima M, Tsumoto T (2001) Activitydependent transfer of brain-derived neurotrophic factor to postsynaptic neurons. Science 291:2419-2423.

Kovalchuk Y, Hanse E, Kafitz KW, Konnerth A (2002) Postsynaptic induction of BDNF-mediated long-term potentiation. Science 295:1729-1734.

Kruttgen A, Moller JC, Heymach Jr JV, Shooter EM (1998) Neurotrophins induce release of neurotrophins by the regulated secretory pathway. Proc Natl Acad Sci USA 95:9614-9619.

Larkfors L, Lindsay RM, Alderson RF (1996) Characterization of the responses of Purkinje cells to neurotrophin treatment. J Neurochem 66:1362-1373.

Lindholm D, Castren E, Tsoulfas P, Kolbeck R, Berzaghi Mda P, Leingartner A, Heisenberg CP, Tessarollo L, Parada LF (1993) Neurotrophin-3 induced by tri-iodothyronine in cerebellar granule cells promotes Purkinje cell differentiation. J Cell Biol 122:443-450.

Lindholm D, Hamner S, Zirrgiebel U (1997) Neurotrophins and cerebellar development. Perspect Dev Neurobiol 5:83-94.

Lu B, Figurov A (1997) Role of neurotrophins in synapse development and plasticity. Rev Neurosci 8:1-12.

Mahata SK, Mahata M, Marksteiner J, Sperk G, Fischer-Colbrie R, Winkler H (1991) Distribution of mRNAs for chromogranins A and B and secretogranin II in rat brain. Eur J Neurosci 3:895-904.

Michael GJ, Averill S, Nitkunan A, Rattray M, Bennett DL, Yan Q, Priestley JV (1997) Nerve growth factor treatment increases brain-derived neurotrophic factor selectively in TrkA-expressing dorsal root ganglion cells and in their central terminations within the spinal cord. J Neurosci 17:8476-8490.

Miller FD, Kaplan DR (2001) On Trk for retrograde signaling. Neuron 32:767-770.

Miyake S, Makimura M, Kanegae Y, Harada S, Sato Y, Takamori K, Tokuda C, 
Saito I (1996) Efficient generation of recombinant adenoviruses using adenovirus DNA-terminal protein complex and a cosmid bearing the full-length virus genome. Proc Natl Acad Sci USA 93:1320-1324.

Morrison ME, Mason CA (1998) Granule neuron regulation of Purkinje cell development: striking a balance between neurotrophin and glutamate signaling. J Neurosci 18:3563-3573.

Mount HT, Dreyfus CF, Black IB (1994) Neurotrophin-3 selectively increases cultured Purkinje cell survival. NeuroReport 5:2497-2500.

Murer MG, Yan Q, Raisman-Vozari R (2001) Brain-derived neurotrophic factor in the control human brain and in Alzheimer's disease and Parkinson's disease. Prog Neurobiol 63:71-124.

Murphy DD, Cole NB, Segal M (1998) Brain-derived neurotrophic factor mediates estradiol-induced dendritic spine formation in hippocampal neurons. Proc Natl Acad Sci USA 95:11412-11417.

Renden R, Berwin B, Davis W, Ann K, Chin CT, Kreber R, Ganetzky B, Martin TF, Broadie K (2001) Drosophila CAPS is an essential gene that regulates dense-core vesicle release and synaptic vesicle fusion. Neuron 31:421-437.

Rettig J, Neher E (2002) Emerging roles of presynaptic proteins in Ca++triggered exocytosis. Science 298:781-785.

Rocamora N, Garcia-Ladona FJ, Palacios JM, Mengod G (1993) Differential expression of brain-derived neurotrophic factor, neurotrophin-3, and low-affinity nerve growth factor receptor during the postnatal development of the rat cerebellar system. Brain Res Mol Brain Res 17:1-8.

Schwartz PM, Borghesani PR, Levy RL, Pomeroy SL, Segal RA (1997) Abnormal cerebellar development and foliation in $\mathrm{BDNF}^{-/-}$mice reveals a role for neurotrophins in CNS patterning. Neuron 19:269-281.

Segal RA, Pomeroy SL, Stiles CD (1995) Axonal growth and fasciculation linked to differential expression of BDNF and NT3 receptors in developing cerebellar granule cells. J Neurosci 15:4970-4981.

Shin OH, Rizo J, Sudhof TC (2002) Synaptotagmin function in dense core vesicle exocytosis studied in cracked PC12 cells. Nat Neurosci 5:649-656.

Shiraishi Y, Mizutani A, Bito H, Fujisawa K, Narumiya S, Mikoshiba K, Furuichi T (1999) Cupidin, an isoform of Homer/Vesl, interacts with the actin cytoskeleton and activated rho family small GTPases and is ex- pressed in developing mouse cerebellar granule cells. J Neurosci 19:8389-8400.

Takada M, Sugimoto T, Hattori T (1993) Tyrosine hydroxylase immunoreactivity in cerebellar Purkinje cells of the rat. Neurosci Lett 150:61-64.

Tandon A, Bannykh S, Kowalchyk JA, Banerjee A, Martin TF, Balch WE (1998) Differential regulation of exocytosis by calcium and CAPS in semi-intact synaptosomes. Neuron 21:147-154.

Velier JJ, Ellison JA, Fisher RS, Vinters HV (1997) The trkC receptor is transiently localized to Purkinje cell dendrites during outgrowth and maturation in the rat. J Neurosci Res 50:649-656.

Verney C, Grzanna R, Farkas E (1982) Distribution of dopamine-betahydroxylase-like immunoreactive fibers in the rat cerebellar cortex during ontogeny. Dev Neurosci 5:369-374.

Voets T, Toonen RF, Brian EC, de Wit H, Moser T, Rettig J, Sudhof TC, Neher E, Verhage M (2001a) Munc18-1 promotes large dense-core vesicle docking. Neuron 31:581-591.

Voets T, Moser T, Lund PE, Chow RH, Geppert M, Sudhof TC, Neher E (2001b) Intracellular calcium dependence of large dense-core vesicle exocytosis in the absence of synaptotagmin I. Proc Natl Acad Sci USA 98:11680-11685.

Walent JH, Porter BW, Martin TF (1992) A novel $145 \mathrm{kd}$ brain cytosolic protein reconstitutes $\mathrm{Ca}^{2+}$-regulated secretion in permeable neuroendocrine cells. Cell 70:765-775.

Wang X, Butowt R, Vasko MR, von Bartheld CS (2002) Mechanisms of the release of anterogradely transported neurotrophin-3 from axon terminals. J Neurosci 22:931-945.

Winkler H (1997) Membrane composition of adrenergic large and small dense cored vesicles and of synaptic vesicles: consequences for their biogenesis. Neurochem Res 22:921-932.

Yuzaki M, Mikoshiba K (1992) Pharmacological and immunocytochemical characterization of metabotropic glutamate receptors in cultured Purkinje cells. J Neurosci 12:4253-4263.

Zhai RG, Vardinon-Friedman H, Cases-Langhoff C, Becker B, Gundelfinger ED, Ziv NE, Garner CC (2001) Assembling the presynaptic active zone: a characterization of an active one precursor vesicle. Neuron 29:131-143. 